\title{
APLIKASI PUPUK UREA PADA PERTUMBUHAN BIBIT JABON MERAH (Anthocephalus macrophyllus (Roxb.) Havil) DI PERSEMAIAN (STUDI KASUS DI IUPHHK PT.TELAGABAKTI PERSADA HALMAHERA SELATAN)
}

\author{
Aplikasi Pupuk Urea pada Pertumbuhan Bibit Jabon Merah (Anthocephalus macrophyllus (Roxb.) \\ Havil) di Persemaian (Studi Kasus di IUPHHK PT.Telagabakti Persada Halmahera Selatan)
}

\author{
Laswi Irmayanti ${ }^{1 *}$, Nurmaya Talib $^{2}$, Salam $^{2}$
}

(Diterima April 2018/ Disetujui Agustus 2019)

\begin{abstract}
Red Jabon (Anthocephalus macrophyllus (Roxb.) Havil.) is one of the fast growing species that became priority to be developed in South Halmahera Regency, North Maluku Province. Currently the red jabon has become "Local Superior Crops" in North Maluku. One of IUPHHK in South Halmahera which develops red jabon is PT. Telagabakti Persada. The purpose of this study was to determine the best growth of red jabon seedling on urea fertilizer application. The study was conducted at PT. Telagabakti Persada, South Halmahera. The treatments of urea fertilizer were $0 \mathrm{~g}, 0.25 \mathrm{~g}, 0.50 \mathrm{~g}$, $0.75 \mathrm{~g}$, and $1 \mathrm{~g}$. The results showed that the urea $0.25 \mathrm{~g}$ fertilizer treatment resulted in the best growth of red jabon seedlings.
\end{abstract}

Key words: Red Jabon, Nursery, Growth of seedling, Urea

\section{PENDAHULUAN}

Jabon merupakan salah satu jenis indigenous yang potensial dan pemanfaatan kayunya saat ini sudah banyak dikenal masyarakat. Ada dua jenis jabon yang dikenal oleh masyarakat yaitu jabon putih (Anthocephalus cadamba Roxb.) dan jabon merah (Anthocephalus macrophyllus (Roxb.) Havil. (Bramasto et al. 2015). Jabon merah lebih dikenal dengan nama lokal samama (Maluku Utara) dan karumama (Sulawesi Utara) (Jafar et al. 2013). Jabon merah merupakan salah satu jenis fast growing species yang menjadi prioritas untuk dikembangkan di Kabupaten Halmahera Selatan, Provinsi Maluku Utara. Saat ini jabon merah telah menjadi TUL (Tanaman Unggul Lokal) di Maluku Utara. Jabon merupakan jenis potensial asli Indonesia yang cepat tumbuh dan multiguna (Soerianegara \& Lemmens 1993; Kartawinata 1994). Menurut Orwa (2009), jabon tergolong tumbuhan pionir yang dapat tumbuh di tanah liat, tanah lempung podsolik cokelat, atau tanah berbatu.

Salah satu IUPHHK di Halmahera Selatan yang mengembangkan jabon merah adalah PT.Telagabakti Persada. Penanaman jabon merah perlu didukung oleh ketersediaan bibit berkualitas dalam jumlah yang cukup pada setiap musim tanam. Pemacuan pertumbuhan bibit jabon dipersemaian dapat dilakukan dengan pemeliharaan secara intensif, salah satunya adalah

\footnotetext{
${ }^{1}$ Program Studi Kehutanan, Fakultas Pertanian,

Universitas Khairun, Ternate, Maluku Utara

${ }^{2}$ Program Studi Kehutanan, Sekolah Tinggi Pertanian

Labuha, Halmahera Selatan, Maluku Utara

* Penulis korespondensi:

E-mail: laswii88@gmail.com
}

penambahan hara melalui pemupukan. Pemupukan merupakan langkah yang nyata dalam memperbaiki nutrisi bibit (Landis 1985). Sahwalita (2015) melaporkan bahwa pemberian pupuk tidak hanya ditujukan agar periode pemelihraan bibit dipersemaian menjadi lebih singkat, tetapi juga agar kualitas bibit yang dihasilkan menjadi lebih baik.

Penelitian pemupukan pada bibit jabon merah dipersemaian saat ini lebih banyak mengunakan pupuk NPK dan Gandasil. Menurut Solikin (2015), pemberian pupuk urea di persemaian memberikan hasil yang cukup menjanjikan, dengan dosis $0 \mathrm{~g} ; 0,4 \mathrm{~g} ; 0,8 \mathrm{~g}$ dan $1,2 \mathrm{~g}$. Berdasarkan hal tersebut, maka perlu adanya studi lebih lanjut untuk menganalisis respon pertumbuhan bibit jabon merah terhadap aplikasi pupuk urea. Tujuan dari penelitian ini adalah menganalisis dosis pupuk urea optimal untuk meningkatkan pertumbuhan bibit jabon merah.

\section{METODE PENELITIAN}

\section{Lokasi dan Waktu}

Penelitian dilaksanakan di Persemaian IUPHHK PT. Telagabakti Persada, Kecamatan Obi Timur, Kabupaten Halmahera Selatan, Provinsi Maluku Utara. Penelitian dilaksanakan selama 6 bulan (September 2016 Februari 2017), yaitu 2 bulan untuk persiapan bibit dan 4 bulan pengamatan pertumbuhan bibit.

\section{Alat dan Bahan}

Bahan yang digunakan dalam penelitian adalah bibit jabon merah (A. macrophyllus) dan pupuk urea. Media bibit jabon yang digunakan adalah murni top soil. 
Sementara ukuran polibag 8 x 15. Alat-alat yang digunakan untuk melakukan pengukuran pertumbuhan bibit adalah kaliper digital, penggaris, alat tulis, kamera digital, dan tally sheet.

\section{Metode}

Metode penelitian terdiri dari beberapa tahapan, yaitu: persiapan benih, pengecambahan, penyapihan, pemupukan, pengamatan pertumbuhan, rancangan percobaan dan analisis data. Proses persiapan bibit mengacu dengan Standar Operasional Prosedur (SOP) pengadaan bibit PT.Telagabakti Persada.

\section{1) Persiapan Benih}

Benih jabon merah yang digunakan dalam penelitian ini berasal dari pohon induk yang ada di PT.Telagabakti Persada. PT.Telagabakti Persada mempunyai 28 pohon induk yang tersebar di hutan Tanjung Jobubu (Sum, pulau Obi, Halmahera Selatan). Pengunduhan dilakukan dengan cara memanjat pohon dan pemungutan buah-buah yang gugur di sekitar pohon induk.

Buah yang sudah terkumpul diekstraksi dengan meremas-remas sampai buah benar-benar hancur, kemudian disaring dengan beberapa tingkat saringan sambil meremas-remas secara berulang agar benih dapat terpisah dari kotoran. Saringan yang digunakan berukuran 420 mikron (35 mesh) dan 250 mikron (60 mesh)

\section{2) Pengecambahan Benih Jabon}

Benih jabon dikecambahkan pada media pasir halus. Lama waktu benih di bedeng tabur selama 1.5 bulan. Benih mulai berkecambah setelah 5-7 hari setelah penaburan. Wadah kecambah ditutup dengan sungkup plastik transparan dengan tujuan untuk mempertahankan kelembapan.

\section{3) Penyapihan}

Media penyapihan yang digunakan adalah murni top soil. Penyapihan dilakukan ketika semai berumur 1.5 bulan setelah penaburan. Normalnya pada saat itu semai masih berbentuk kecambah dengan sekitar dua daun. Semai ditanam pada media sapih yang sebelumnya telah dijenuhkan dengan air dan dibuatkan lubang dengan menggunakan stik kayu yang diperkirakan kedalamannya sebatas leher akar kemudian tanah dipadatkan kembali sampai rapat dan tidak goyah.

\section{4) Cara Pemupukan}

Pemupukan dilakukan satu minggu setelah bibit dipindahkan ke bedeng sapih. Pupuk yang sudah ditimbang kemudian ditaburkan dalam media sapih secara melingkar mengikuti pinggiran polibag.

\section{5) Variabel Pengukuran}

Pengukuran variabel pertumbuhan bibit yang dilakukan meliputi tinggi, diameter, dan jumlah daun (Ditjen RLPS 2012). Pengukuran tinggi dan diameter serta jumlah daun semai dilakukan 2 minggu sekali. Tinggi tanaman diukur dengan penggaris. Tinggi tanaman diukur $1 \mathrm{~cm}$ dari pangkal batang sampai ke ujung titik pertumbuhan (pucuk). Titik pangkal batang diseragamkan dengan tancapan lidi yang diberi tanda permanen untuk menghindari kesalahan akibat kembang kempis tanah pasca penyiraman. Diameter diukur dengan kaliper. Pengukuran diameter dilakukan $1 \mathrm{~cm}$ di atas pangkal batang. Selain tinggi, diameter dan jumlah daun variabel pertumbuhan yang diukur adalah kekokohan batang. Kekokohan batang merupakan perbandingan antara tinggi $(\mathrm{cm})$ terhadap diameter $(\mathrm{mm})$ yang diukur di akhir pengamatan (Huriati 2001, Rahayu \& Wahyuni 2016).

\section{6) Rancangan Percobaan}

Rancangan percobaan yang digunakan adalah Rancangan Acak Lengkap (RAL) yaitu mengacu pada Mattjik dan Sumertajaya (2013), serta Gomez dan Gomez (2007). Perlakuan yang diterapkan adalah perbedaan dosis pupuk urea meliputi 5 perlakuan, yaitu P1 (kontrol $0 \mathrm{~g}), \mathrm{P} 2(0.25 \mathrm{~g}), \mathrm{P} 3$ (0.50 g), P4 (0.75 g), dan P5 (1 g). Setiap perlakuan diulang sebanyak 3 kali, dan masing-masing unit percobaan diulang 3 kali. Sehingga total bibit jabon merah yang digunakan adalah $3 \times 3 \times 5=45$ buah. Model linier rancangan penelitian yang digunakan yaitu (Mattjik dan Sumertajaya 2013) :

keterangan:

$$
\mathbf{Y}_{\mathrm{ij}}=\boldsymbol{\mu}+\mathbf{T}_{\mathbf{i}}+\boldsymbol{\epsilon}_{\mathrm{ij}}
$$

$\mathrm{Y}_{\mathrm{ij}}$ : pengamatan pada perlakuan ke-i dan ulangan ke-j

$\mu \quad$ : rataan umum

$\mathrm{T}_{\mathrm{i}}$ : pengaruh perlakuan ke-i

$€_{\mathrm{ij}}$ : pengaruh acak pada perlakuan ke-i dan ulangan ke-j

\section{7) Analisis Data}

Analisis yang digunakan untuk menguji pengaruh perlakuan terhadap variabel yang diamati adalah analisis sidik ragam (Mattjik \& Sumertajaya 2013). Apabila perlakuan berpengaruh nyata terhadap variabel yang diukur, maka dilanjutkan uji jarak berganda (duncan's multiple range testDMRT) dengan bantuan software SAS 9.0 (SAS Institute Inc 2006).

\section{HASIL DAN PEMBAHASAN}

Berdasarkan hasil pengukuran bibit jabon di persemaian menunjukkan bahwa pertumbuhan tinggi bibit jabon merah paling tinggi adalah pada dosis $0.50 \mathrm{~g}$ pupuk urea. sementara pertumbuhan diameter bibit paling besar adalah pada dosis $0.25 \mathrm{~g}$ (Gambar 1 dan 2). Pada dosis tersebut merupakan dosis optimum untuk ketersedian hara dalam pertumbuhan. Ketersediaan unsur hara yang optimal akan membuat proses fisiologis didalam tanaman berjalan baik. Haase (2004) 
melaporkan bahwa pengukuran pertumbuhan berupa tinggi dan diameter bibit merupakan dua variabel yang sering digunakan untuk menentukan mutu bibit secara morfologi. Pada pengamatan jumlah daun pada semua perlakuan menunjukkan pertambahan jumlah daun yang sama (Gambar 3).

Kenaikan dosis pupuk urea sampai $1 \mathrm{~g}$ justru didapatkan hasil pertumbuhan yang rendah. Hal ini disebabkan pada dosis tersebut unsur hara sudah diatas optimal. Ketersediaan unsur hara yang optimal akan membuat proses fisiologis didalam tanaman berjalan baik, terutama unsur hara yang berperan dominan dalam pertumbuhan vegetatif (Ambarwati 2008). Sehingga pada ketersediaan hara dibawah dan diatas optimal akan menghambat proses pertumbuhan.

Uji lanjut Duncan dengan $\alpha=0.50$ menunjukkan bahwa dosis pupuk urea memberikan pengaruh yang nyata terhadap pertumbuhan tinggi dan diameter bibit jabon merah (Gambar 1 dan 2). sementara pada pertambahan jumlah daun, pupuk urea tidak memberikan pengaruh yang nyata (Gambar 3).

Gambar 1 menunjukkan bahwa perlakuan pupuk urea pada dosis $0.25 \mathrm{~g}, 0.50 \mathrm{~g}$, dan $0.75 \mathrm{~g}$ memberikan respon tinggi bibit jabon merah yang lebih tinggi dibandingkan dosis $0 \mathrm{~g}$ dan $1 \mathrm{~g}$. Ukuran polibag yang digunakan dalam penelitian ini yaitu $8 \times 15 \mathrm{~cm}$ dengan media topsoil. Hal ini bisa dikatakan bahwa dosis $1 \mathrm{~g}$ sudah melebihi unsur hara yang dibutuhkan bibit pada polybag ukuran $8 \times 15 \mathrm{~cm}$. Menurut Sapsuha et al. (2012), dalam pemberian pupuk perlu diperhatikan kebutuhan hara pada tanaman yang akan dipupuk, agar tanaman tidak mendapat terlalu banyak zat makanan. Terlalu sedikit atau terlalu banyak zat makanan dapat berbahaya bagi tanaman. Pertumbuhan tinggi bibit terendah adalah pada kontrol $(0 \mathrm{~g})$.

Berdasarkan Gambar 1 juga dapat dilihat bahwa perlakuan pupuk urea pada dosis $0.25 \mathrm{~g}, 0.50 \mathrm{~g}$, dan $0.75 \mathrm{~g}$ memberikan respon yang sama. Hal ini menunjukkan penggunaan pupuk urea pada dosis 0.25 $\mathrm{g}, 0.50 \mathrm{~g}$, dan $0.75 \mathrm{~g}$ akan menghasilkan pertumbuhan tinggi bibit yang sama.

Berdasarkan Gambar 2 didapatkan bahwa respon

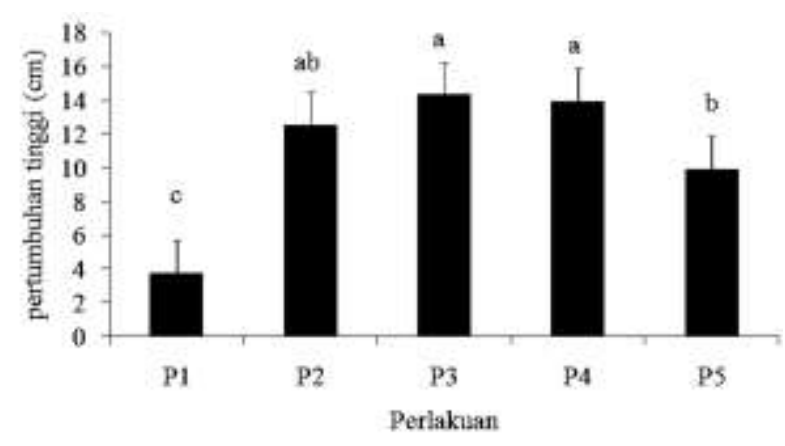

Gambar 1 Pertumbuhan tinggi bibit jabon merah pada setiap perlakuan (P1:0g, P2:0.25g, P3:0.50g, P4:0.75g, dan P5:1g) (hurufhuruf di atas balok menunjukkan perbandingan nilai tengah tiap perlakuan dan huruf yang sama menunjukkan tidak berbeda nyata pada taraf uji selang berganda Duncan 5\%) tertinggi pertumbuhan diameter bibit jabon merah adalah pada dosis $0.25 \mathrm{~g}$. Dosis tersebut memberikan respon yang berbeda dari dosis yang lainnya. Hal ini bisa dikatakan bahwa pada dosis $0.25 \mathrm{~g}$ akan menghasilkan pertumbuhan diameter bibit terbaik. Pada dosis tersebut merupakan dosis optimum untuk ketersedian hara dalam pertumbuhan. Ketersediaan unsur hara yang optimal akan membuat proses fisiologis didalam tanaman berjalan baik. Hal ini sesuai yang dipaparkan oleh Ambarwati (2008) bahwa ketersediaan unsur hara yang optimal akan membuat proses fisiologis didalam tanaman berjalan baik, terutama unsur hara yang berperan dominan dalam pertumbuhan vegetatif.

Gambar 3 menunjukkan bahwa pupuk urea pada semua perlakuan memberikan respon yang sama pada pertambahan jumlah daun bibit jabon. Namun berdasarkan hasil pengamatan didapatkan bahwa dosis $0.25 \mathrm{~g}, 0.50 \mathrm{~g}$, dan $0.75 \mathrm{~g}$ yang diberikan kepada bibit jabon merah mempunyai luas daun yang lebih besar dibandingkan dengan dosis $0 \mathrm{~g}$ dan dosis $1 \mathrm{~g}$.

Pertumbuhan tanaman jabon sangat dipengaruhi oleh faktor internal dan eksternal. Faktor internal adalah kualitas dari bibit itu sendiri, dan faktor eksternal adalah lingkungan. Salah satu faktor lingkungan yang turut berperan dalam proses pertumbuhan tanaman adalah unsur hara dalam tanah. Salah satu unsur hara makro yang diperlukan untuk pertumbuhan adalah nitrogen $(\mathrm{N})$ yang mana unsur $\mathrm{N}$ diperlukan dalam pembentukan dan pertumbuhan bagian-bagian vegetatif, seperti batang dan daun. Unsur $\mathrm{N}$ dalam kadar tinggi salah satunya bisa didapatkan pada pupuk urea.

Nirogen merupakan zat hara yang sangat diperlukan oleh tanaman. Salah satu manfaatnya adalah untuk mempercepat pertumbuhan tanaman (tinggi, jumlah anakan, cabang, dan lain-lain). Studi hasil penelitian Nurahmi et al. (2013) terdapat interaksi yang nyata antara perlakuan dosis pupuk urea dan umur bibit terhadap tinggi, diameter batang, jumlah daun, luas daun, panjang akar, dan berat kering bibit kakao.

Berdasarkan hasil penelitian ini, dapat direkomendasikan bahwa penggunaan pupuk urea yang optimal untuk pemupukan bibit jabon merah pada media

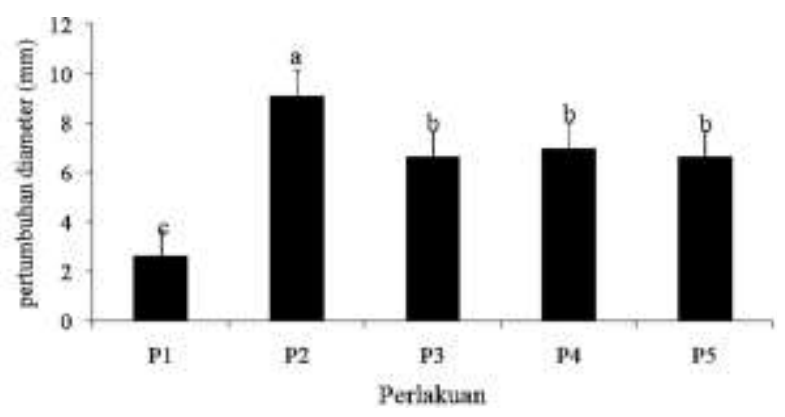

Gambar 2 Pertumbuhan tinggi diameter jabon merah pada setiap perlakuan (P1:0g, P2:0.25g, $\mathrm{P} 3: 0.50 \mathrm{~g}, \mathrm{P} 4: 0.75 \mathrm{~g}$, dan P5:1g) (hurufhuruf di atas balok menunjukkan perbandingan nilai tengah tiap perlakuan dan huruf yang sama menunjukkan tidak berbeda nyata pada taraf uji selang berganda Duncan 5\%) 
topsoil dan ukuran polybag $8 \times 15$ adalah pada dosis 0.25 gr. Menurut Ferdousee et al. (2010), kenaikan performa pertumbuhan bibit sejalan dengan kenaikan ukuran polibag, yaitu polibag dengan ukuran lebih besar akan memberikan kenaikan daya survival pada bibit. Sehingga untuk mensuplai hara secara optimal, kenaikkan ukuran polybag yang digunakan dalam pembibitan harus diikuti dengan kenaikan dosis pupuk urea yang digunakan.

Indikator daya adaptasi tanaman di lapangan bisa dilihat dari nilai kekokokan bibit (Suryawan et al. 2016). Nilai kekokohan bibit yang rendah menunjukkan kemampuan hidup yang tinggi. Adinugroho (2012) memaparkan bahwa nilai kekokohan bibit yang tinggi menunjukkan kemampuan hidup yang rendah karena tidak seimbangnya perbandingan antara tinggi batang dan diameternya. Nilai kekokohan bibit pada penelitian ini didapatkan nilai yang rendah pada semua perlakuan (Gambar 4) yaitu dibawah 1.20. Hal ini menunjukkan bahwa kemampuan bibit untuk hidup pada semua perlakuan dikategorikan tinggi. Adinugroho (2012) juga memaparkan bahwa nilai kekokohan bibit yang masih optimum adalah sebesar 4-5.

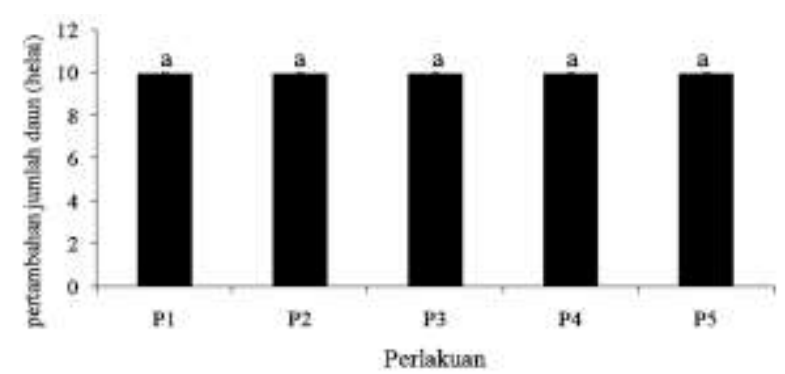

Gambar 3 Pertambahan jumlah daun jabon merah pada setiap perlakuan $(\mathrm{P} 1: 0 \mathrm{~g}, \mathrm{P} 2: 0.25 \mathrm{~g}$, $\mathrm{P} 3: 0.50 \mathrm{~g}, \mathrm{P} 4: 0.75 \mathrm{~g}$, dan $\mathrm{P} 5: 1 \mathrm{~g}$ ) (hurufhuruf di atas balok menunjukkan perbandingan nilai tengah tiap perlakuan dan huruf yang sama menunjukkan tidak

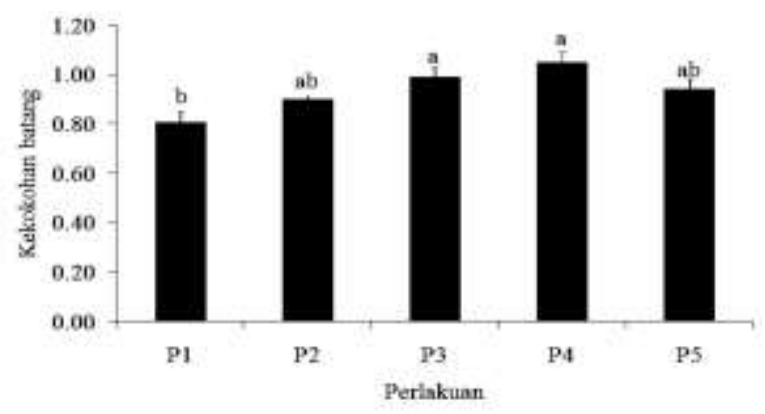

Gambar 4 Kekokohan batang bibit jabon merah pada setiap perlakuan (P1:0g, P2:0.25g, P3:0.50g, P4:0.75g, dan P5:1g) (hurufhuruf di atas balok menunjukkan perbandingan nilai tengah tiap perlakuan dan huruf yang sama menunjukkan tidak berbeda nyata pada taraf uji selang berganda Duncan 5\%)

\section{SIMPULAN}

Pemberian pupuk urea mempengaruhi pertumbuhan diameter dan tinggi bibit jabon merah. Pemberian pupuk urea tidak mempengaruhi pertambahan jumlah daun bibit merah. Pemberian dosis pupuk optimal pada pertumbuhan bibit jabon dengan ukuran polybag $8 \times 15$ $\mathrm{cm}$ adalah pada dosis $0.25 \mathrm{~g}$.

\section{DAFTAR PUSTAKA}

Adinugraha HA. 2012. Pengaruh cara penyemaian dan pemupukan NPK terhadap pertumbuhan bibit mahoni daun lebar di pesemaian. [internet]. [diunduh 2019 Jul 31]. Tersedia pada :http://fordamof.org/files/1.Pengaruh_Cara_Penyemaian_dan_ Pemupukan_NPK-Hamdan_Adma.pdf

Ambarwati R. 2008. Kajian dosis pupuk urea dan macam media tanam terhadap hasil kandungan andrographolide tanaman sambiloto (Andrographis paniculata Ness) [tesis]. Surakarta: Universitas Sebelas Maret.

Bramasto Y, Sudrajat DJ, Rustam EY. 2015. Diversity of morphology Anthocephallus macrophyllus and Anthocephallus cadamba depend on the dimension of fruit, seed and leaves. Pros Sem Nas Masy Biodiv Indon. 1 (6):1278-1283.

[Ditjen RLPS] Direktorat Jenderal Rehabilitasi Lahan dan Perhutanan Sosial. 2012. Standar Mutu Bibit Tanaman Hutan. Jakarta (ID): Direktorat Perbenihan Tanaman Hutan.

Ferdousee N, Jabbar F, Hossain MK, Hoque ATMR. 2010. Comparative growth performance of Leucaena leucocephala seedlings raised in nursery bed, polybag and root trainers. Proc. of International Conference on Environmental Aspects of Bangladesh (ICEAB10), Japan Sept 2010. Hal 65-68.

Gomez KA, Gomez AA. 2007. Prosedur Statistik untuk Penelitian Pertanian. Sjamsuddin E, Baharsjah JS, penerjemah. Jakarta (ID): UI Press. Terjemahan dari: Statistical Procedures for Agricultural Research.

Haase DL. 2004. Understanding Forest Seedling Quality: Measurements and Interpretation. Tree Planters's Notes. 52(2):24-30

Huriati E. 2001. Studi Variasi Pertumbuhan Acacia mangium Willd dari Berbagai Provenans, di Persemaian HTI Subanjeriji, PT.Musi Hutan Persada Sumatera Selatan. Bogor: Institut Pertanian Bogor.

Jafar SH. Thomas A, Kalangi JI, Lasut MT. 2013. Pengaruh Frekuensi Pemberian Air terhadap Pertumbuhan Bibit Jabon Merah (Anthocephalus macrophyllus (Roxb.) Havil).

Kartawinata K. 1994. The use of secondary forest species in rehabilitation of degraded forest lands. $J$ of Tropical Forest Science 7(1):76-86.

Landis TD. 1985. Mineral nutrition as an index of seedling quality. Di dalam: Duryea ML, editor. 
Proceedings: Evaluating seedling quality: principles, procedures, and predictive abilities of major tests. October 16-18, 1984. Forest Research Laboratory, Oregon State University, Corvallis.

Mattjik AA, Sumertajaya IM. 2013. Perancangan Percobaan dengan Aplikasi SAS dan Minitab. Bogor (ID): IPB Press.

Nurahmi E, Yunus Y, Yennita. 2013. Pengaruh umur kecambah dan dosis pupuk urea terhadap pertumbuhan bibit kakako. Floratek. 1(8):10-17

Orwa C, Mutua A, Kindt R, Jamnadass R, Anthony S. 2009. Agroforestry tree database: a tree reference and selection guide version 4.0. Agroforestry Database (4.0) [internet]. [diunduh 2011 Juli 16]. Tersedia

pada:http://www.worldagroforestry.org/treedb2/A FTPDFS/Anthocephalus_cadamba. pdf.

Rahayu AAD, Wahyuni R. 2016. Pengaruh media organik sebagai media sapih terhadap kualitas bibit bidara laut (Strychnos lucida R.Brown). J Pemuliaan Tanaman Hutan. 10(1):13-21.

Sahwalita. 2015. Pengaruh pupuk daun pada pertumbuhan bibit sungkai di persemaian. Di dalam: Mindawati L, Bramasto Y, Pramono AA, Rahmat M, editor. Teknologi Perbenihan, Silvikultur dan Kelembagaan dalam Peningkatan Produktivitas Hutan dan Lahan. Prosiding
Seminar Hasil Penelitian Balai Penelitian Teknologi Perbenihan Tanaman Hutan, Balai Penelitian Kehutanan Palembang, 11 Agustus 2015; Bandar Lampung. Bogor (ID): Pusat Penelitian dan Pengembangan Hutan, Kementerian Lingkungan Hidup dan Kehutanan.

Sapsuha R, Thomas A, Lasu MT, Rombang JA. 2012. Pengaruh pemupukan NPK terhadap pertumbuhan bibit jabon putih (Anthocephalus cadamba (Roxb.) Miq.

SAS Institute Inc. 2006. Base SAS® 9.1.3 Procedures Guide Edisi ke-2. North Carolina (US): SAS Institute Inc.

Soerianegara I, Lemmens RHMJ. 1993. Plant resources of South-East Asia 5(1): Timber trees: major commercial timbers. Wageningen (NL): Pudoc Scientific Publishers.

Solikin. 2015. Pengaruh tinggi bibit dan dosis pupuk urea terhadap pertumbuhan tanaman Stachytarpheta jamaicensis. Pros Sem Masy Biodiv Indon. 1(5):1177-1181. Doi:10.13057/psnmbi /m010537

Suryawan A, Cristita M, Subiandono E. 2016. Daya hidup, pertumbuha dan indeks mutu stump Baringtonia asiatica Kurz pada berbagai variasi panjang batang dan akar. J Wasiana. 3(2):97-104. 